\title{
HYBRID TECHNIQUE FOR SALVAGE OF ACUTELY FAILED DIALYSIS ACCESS; FEASIBILITY, SHORT AND MID TERM RESULTS
}

\author{
Ayman Essawy $^{(1)}$, Amr El Bahaey ${ }^{(2)}$, Ahmed Abdelrahman Ahmed ${ }^{(1) *}$, Ibrahim \\ Madian Mahmoud ${ }^{(1)^{*}}$
}

(1) Faculty of Medicine, Fayoum University

(2) Faculty of Medicine, Cairo University

Corresponding author: Ibrahim Madian Mahmoud

E mail address: ibrahimmadian0@gmail.com

Tel: $002-01008959498$

\begin{abstract}
Background: Thrombectomy is the most common surgical technique used to reestablish failed hemodialysis access. Then percutaneous thrombectomy was introduced. To achieve better patient outcomes, hybrid technique with combined open thrombectomy and angioplasty has been introduced in recent years.
\end{abstract}

Aim of the study: To evaluate the hybrid technique by surgical Fogarty thrombectomy and balloon angioplasty in salvage of acutely failed dialysis access regarding feasibility, early and mid term results.

Patients and methods: This case series prospective study was conducted at Fayoum University Hospital and Cairo University Hospitals between December 2017 and October 2018. It included 20 patients; $12(60 \%)$ males and $8(40 \%)$ females with a mean age of $52.9 \pm$ 15.3 years. All patients had acutely failed hemodialysis access that was subjected to hybrid salvage with combined open

KEY WORDS: hybrid, hemodialysis access, failed, salvage, thrombectomy, angioplasty. thrombectomy and angioplasty. Outcome was evaluated regarding clinical success and 6 months primary patency.

Results: All 20 patients were subjected to hybrid thrombectomy and angioplasty. Type of access included radial cephalic (20\%), brachial cephalic $(50 \%)$, brachial basilic $(20 \%)$ and brachial axillary graft $(10 \%)$. Mean age of access was $23.9 \pm 21.1$ months and mean interval between access thrombosis and intervention was 8.6 \pm 3.4 days. The immediate clinical success rate was $80 \%$. The primary patency rates at $1 \mathrm{~m}$ and $6 \mathrm{~m}$ were $78.9 \%$ and $72.2 \%$, respectively.

Conclusion: hybrid salvage technique using combined open thrombectomy and angioplasty provides acceptable patency by removal of thrombus and correction of associated stenosis of acutely failed hemodialysis access. 


\section{INTRODUCTION}

End-stage renal disease (ESRD) is a huge public health problem with significant morbidity, mortality, and cost. ${ }^{(1)}$ Hemodialysis remains the commonest mode of renal replacement therapy for ESRD patients worldwide. ${ }^{(2)}$

Appropriate care of hemodialysis patients with chronic kidney disease stage 5 requires constant attention to the maintenance of vascular access patency and function. ${ }^{(3)}$

Failure of vascular access in hemodialysis patients is one of the most common referrals that vascular surgeons encounter. Because of the poor patient outcomes due to vascular access thrombosis, several treatment methods have been developed to deal with this problem. ${ }^{(4)}$

In most patients, thrombosis is the final complication after a period of dialysis access dysfunction. The vascular access should be reopened as soon as possible to resume regular dialysis treatment and avoid resorting to a short-term catheter. ${ }^{(5)}$

Traditionally, surgical thrombectomy, with or without revision surgery, was the

\section{PATIENTS AND METHODS}

As a descriptive prospective case series study, the study was conducted at Fayoum University Hospital and Cairo University Hospitals between December 2017 and October 2018. It included $20 \mathrm{HD}$ patients with acutely failed HD access.

Candidate patients were scheduled for salvage procedure after referral from dialysis centers for failed HD access. Pre operative assessment including clinical, routine laboratory investigations and radiological assessment were done to confirm diagnosis of recently failed access and to detect site of stenosis or occlusion (Fig7). Duplex was done to visualize arterial inflow to exclude arterial stenosis or thrombosis and to assess outflow lesions. Exposure of juxtaanastomotic segment the vein or graft was done under local or regional anesthesia. primary method employed by vascular surgeons to re-establish vascular access. ${ }^{(6,7)}$ Other less invasive methods, such as thrombolytic therapy or percutaneous mechanical thrombectomy also were introduced with the disadvantage that thrombus might be left in the access, that could embolize into the pulmonary circulation. ${ }^{(8)}$

In hybrid technique the two components of successful dialysis access thrombectomy are removal of the thrombus and treatment of the underlying cause of access failure, removal of thrombus is best achieved by open balloon thrombectomy. Once the thrombus is removed, complete imaging from the arterial inflow to the superior vena cava can be performed. With this approach, treatment of any remote, underlying lesion can be accomplished by techniques normally reserved for percutaneous treatment. Finally, any venous anastomotic stenoses can be treated with balloon angioplasty, thereby preserving the available length of the outflow vein, frequently compromised with the open, surgical approaches. ${ }^{(9,10)}$

Thrombectomy was performed by placing a Fogarty catheter 4 or 5 french within the proximal and distal tract. Then both sides of the track are heparinized, by administering a single dose of $2500 \mathrm{IU}$ intravenous heparin in each side.

If large aneurysm was present, elliptical vertical incision is made at site of aneurysm in order to do partial aneurysmectomy after surgical thrombectomy.

Sheath 6 French was embedded through thrombectomy incision. Sometimes radial artery sheath was used in cases with juxtaanastomotic lesions. Then the upper extremity and central venous venography were performed. After determining the location of any lesions, crossing the lesion was done using angled hydrophilic $260 \mathrm{~cm}$ 
0.035 " guide wire (Zip or Terumo) over 5

French selective vertebral (Bernstein) catheter.

After crossing the lesion, balloon angioplasty with a 6-8 $\mathrm{mm}$ high pressure balloon (Mustang) was performed. Then

\section{RESULTS}

Study included 20 patients; 12 (60\%) males and $8(40 \%)$ females with a mean age of $52.9 \pm$ 15.3 years. Outcome was evaluated regarding clinical success and 6 months primary patency. Clinical success was defined as the successful restoration of AVF flow with satisfactory dialysis utilizing the restored access after the procedure. ${ }^{(11)}$ Primary patency was calculated from the date of the initial salvage procedure to the next subsequent access intervention or thrombosis. ${ }^{(11)}$

Type of access included radial cephalic (20\%), brachial cephalic (50\%), brachial basilic (20\%) and brachial axillary graft $(10 \%)$. Mean age of access was $23.9 \pm 21.1$

\section{DISCUSSION}

Surgical thrombectomy and patch angioplasty were common treatments for vascular access failure in hemodialysis patients, which can be performed in a short time and are very effective. These methods were the most effective in treating segmental lesions, but in multilevel and central lesions, surgeons perform thrombectomy along with other procedures to increase the immediate and long term prognosis. ${ }^{(12)}$

Using less invasive approaches, such as thrombolytic therapy or mechanical thrombectomy, requires longer surgical times and are more expensive. In addition, these methods usually were not as effective as open surgical thrombectomy and may cause systemic thrombolytic complications, such as bleeding. Furthermore, these methods also required patients to use a temporary dialysis catheter for their first hemodialysis session. ${ }^{(13)}$

Combined surgical thrombectomy with endovascular treatment for salvage of completion angiography was done to confirm the procedure success.

After completion of procedure, venotomy or graftotomy was closed with $6 / 0$ polypropylene sutures.

months and mean interval between access thrombosis and intervention was 8.6 \pm 3.4 days. Regarding complications $15 \%$ had failure of procedure, $5 \%$ had vein rupture during procedure that end up with ligation of access and failure of procedure, $5 \%$ had bleeding caused by vessel tearing during balloon angioplasty, were successfully controlled by external compression, 5\% had superficial infection that was managed by broad spectrum antibiotic, $70 \%$ had no complication.

The immediate clinical success rate was $80 \%$. The primary patency rates at $1 \mathrm{~m}$ and 6 $\mathrm{m}$ were $78.9 \%$ and $72.2 \%$, respectively.

thromobsed access have been introduced, to obtain the synergy effect of both surgical and endovascular treatment and to improve the technical success rate. Hybrid surgery is able to remove thrombus feasibly in the surgical fields and correct underlying causative lesions disclosed by the intraoperative fluoroscopy and angioplasty..$^{(14,15)}$

The success rate of our procedure was $80 \%$ Primary patency rate at $1 \mathrm{~m}$ and $6 \mathrm{~m}$ was $78.8 \%$ and $72.2 \%$, respectively.

As regards other previous studies on hybrid technique, Ko PJ, et al. reported a study of 13 patients with thrombosed access that their 1month and 6 months primary patency after salvage was $77 \%$ and $38 \%$ respectively. Daavodi M. et al. reported a study of 53 patients with the immediate success rate, 1month and 6 months primary patency was $85 \%, \quad 75 \%$ and $55 \%$ respectively. Gupta $\mathrm{P}$, et al. studied 55 cases with patency rate was $76 \%$ on first postoperative day and 68\% at 6 months. 
Hyun J., et al. reported technical success rate $(92.5 \%)$ and primary patency $(85.9 \%$ at 6 months). Results of our study was comparable to other studies regarding clinical success rate and the 6 months primary patency. ${ }^{(10,11,16,17)}$

Compared to results of open thrombectomy without surgical revision, Brotman et al. reported 1 month and 6 month primary patency of $30 \%$ and $10 \%$ respectively. ${ }^{(18)}$

In comparison with open thrombectomy with surgical revision, Brotman et al. reported 1 month and 6 month primary patency of $59 \%$ and $25 \%$ respectively. Dapunt et al. reported 1 month and 5 months primary patency of $64.1 \%$ and $28.9 \%$ respectively. ${ }^{(15,18)}$

Compared to percutaneos mechanical thrombectomy, Jain et al. studied 41 cases and reported technical success rate $(76 \%)$ and primary patency at 6 months $(20 \%)$. Lee

\section{REFERENCES}

[1] U.S. Renal Data System: USRDS annual data report: atlas of end stage renal disease in the United States, Bethesda, MD, 2012, National Institutes of Health, National Institute of Diabetes and Digestive and Kidney Diseases, 2012.

[2] Vathsala, "Twenty-five facts about kidney disease in Singaporeinremembrance of world kidney day," Annals of theAcademy of Medicine Singapore, vol. 36, no. 3, pp. 157-160, 2007.

[3] Pisoni RL, Young EW, Dykstra DM, et al: Vascular access use in Europe and the United States: Resultsfrom the DOPPS. Kidney Int. 61:305-316, 2002.

[4] Miller PE, Carlton D, Deierhoi MH, Redden DT, Allon M Natural history of arteriovenous grafts in hemodialysis patients. Am J Kidney Dis. 36: 68-74, 2000.

[5] Foundation NK. KDOQI clinical practice guidelines and clinicalpractice recommendations for 2006 updates: hemodialysisadequacy, peritoneal et al. studied the practice of mechanical thrombectomy on 67 cases, with or without thrombolytic agents, and reported an immediate success rate of $89.3 \%$, but at 6 month follow-up, the vascular access patency declined to $25.6 \%$. Hyun J., et al. reported technical success rate $(68.4 \%)$ and primary patency $(36.8 \%$ at 6 months) of percutaneous mechanical thrombectomy. Other studies reported comparable results regarding immediate clinical success and 6 month primary patency. ${ }^{(14,17,19)}$

We conclude that hybrid salvage technique using combined open thrombectomy and angioplasty provides acceptable patency by removal of thrombus and correction of associated stenosis of acutely failed hemodialysis access and avoids disadvantages of each procedure alone.

dialysis adequacy and vascular access. AmJ Kidney Dis. 48(Suppl. 1):S1eS309,2006.

[6] Wellington JL Salvage of thrombosedpolytetrafluoroethylene dialysis fistulas by interposition grafting. Can J Surg. 26: 463-465, 1983.

[7] Bell DD, Rosental JJ Arteriovenous graft life in chronic hemodialysis: A need for prolongation. Arch Surg. 123: 1169-1172, 1988.

[8] Himmelfarb J, Saad T Hemodialysis vascular access: emerging concepts. CurrOpinNephrolHypertens. 5: 485-491, 1966.

[9] Criado E, et al: Thrombosedpolytetrafluoroethylene hemodialysis fistulas: salvage with combined thrombectomy and angioplasty. Radiology. 171:507-508, 1989.

[10] Ko PJ, et al: Initial experience during balloon angioplasty assisted surgical thrombectomy for thrombosed 
hemodialysis grafts. Chang GungMed J.26:178-183, 2003.

[11] Gray RJ, Sacks D, Martin LG, Trerotola SO: Reporting standards for percutaneous interventions in dialysis access. J VascIntervRadiol 14:S433S442, 2003.

[12] M. Davoodi, H. Farsavian and A. Farsavian, "Hybrid Therapy Using a Surgical Thrombectomy with a Balloon Angioplasty to Regain Thrombosed Dialysis Vascular Access-Clinical Case Series", Surgery: Current Research, vol. 07, no. 01, 2017.

[13] Lombardi JV, Dougherty MJ, Veitia $\mathrm{N}$, Somal J, Calligaro KD: A comparison of patch angioplasty and stenting for axillary venous stenoses of thrombosed hemodialysis grafts. Vasc Endovascular Surg 36: 223-229, 2002.

[14] Jain G, Maya ID, Allon M. Outcomes of percutaneous mechanical thrombectomy of arteriovenous fistulas in hemodialysis patients. Semin Dial 21:581-3, 2008.

[15] Palmer RM, Cull DL, Kalbaugh C, Carsten CG, Taylor SM, Snyder BA, et al. Is surgical thrombectomy to salvage failed autogenous arteriovenous fistulae worthwhile? Am Surg. 72:1231-3, 2006.

[16] P. Gupta, V. Yerramsetty, P. Burli, P. Sharma, M. Nagiredy and V. Kulkarni, "FT13. Hybrid Salvage for Thrombosed Autogenous Hemodialysis Access", Journal of Vascular Surgery, vol. 65, no. 6, p. 20S, 2017.

[17] Hyun, J., Lee, J. and Park, S. Hybrid surgery versus percutaneous mechanical thrombectomy for the thrombosed hemodialysis autogenous arteriovenous fistulas. Journal of the Korean Surgical Society, 81(1), p.43, 2011.

[18] Brotman DN, Fandos L, Faust GR, Doscher W, Cohen JR: Hemodialysis graft salvage. J Am CollSurg 178: 431434, 1994.

[19] Lee, H. and Park, P. Clinical outcome of percutaneous thrombectomy of dialysis access thrombosis by an interventional nephrologist. Kidney Research and Clinical Practice, 33(4), pp.204-209, 2014. 